\title{
Níveis de Energia no Desempenho e Características da Carcaça de Cordeiros Alimentados em Creep Feeding ${ }^{1}$
}

\section{Cledson Augusto Garcia ${ }^{2}$, Ciniro Costa ${ }^{3}$, Alda Lúcia Gomes Monteiro ${ }^{4}$, Marcela Abbado Neres ${ }^{5}$, Guilherme Jordão Magalhães Rosa ${ }^{6}$}

\begin{abstract}
RESUMO - O trabalho foi realizado no Setor de Ovinocultura da Universidade de Marília, objetivando estudar os efeitos de três níveis de energia (2,6; 2,8 e 3,0 Mcal EM/kg MS) na ração de cordeiros inteiros Suffolk criados em creep feeding, sobre o desempenho e características de carcaça. Na parição numerava-se e registravam-se o peso ao nascer dos cordeiros que, posteriormente, foram distribuídos aleatoriamente, compondo doze repetições por tratamento. As rações foram isoprotéicas $(18,46 \%$ PB) fornecidas ad libitum duas vezes ao dia, pesandose as respectivas sobras. Os cordeiros foram pesados a cada 14 dias, permanecendo com as ovelhas até atingirem o peso vivo final, preestabelecido em $31 \mathrm{~kg}$. Em seguida, os cordeiros permaneceram em jejum alimentar por 16 horas, até o momento do abate, obtendo-se o peso vivo ao abate. Após o abate, registraram-se os pesos da carcaça quente e do conteúdo digestivo, para o cálculo do peso de corpo vazio. As carcaças permanecerem por 24 horas na câmara de refrigeração em temperatura de $5^{\circ} \mathrm{C}$, obtendo-se o peso da carcaça fria. Para o ganho médio diário ocorreu diferença significativa entre os tratamentos, utilizando-se como covariável a idade de abate, com melhor desempenho para os cordeiros que receberam a ração com 3,0 Mcal EM. Para as características da carcaça não houve efeito dos tratamentos. Concluiuse que o nível 3,0 Mcal EM foi o mais indicado para a ração de cordeiros Suffolk alimentados e terminados em creep feeding.
\end{abstract}

Palavras-chave: comedouro seletivo, crescimento dos ovinos, suplementação

\section{Performance and Carcass Traits of Lambs Fed Diets with Different Energy Levels Grown in Creep Feeding}

\begin{abstract}
The experiment was carried out at Sheep Production Department, Universidade de Marília-SP, to evaluate the effect of rations with three energy levels fed to Suffolk lambs grown in creep feeding, on performance and carcass traits. At birth, lambs were identified, weighed and, then, randomly allotted to the treatments, with 12 replications for different energy levels. Lambs fed isoproteins rations ad libitum, twice a day, and orts were daily recorded. Lambs were weighed at each 14 days and stayed with their dams until final live weight, $31 \mathrm{~kg}$. After, lambs were fasted for $16 \mathrm{~h}$ until slaughter, when slaughter live weight was recoded. Hot carcass weight and digestive content were recorded to estimate empty live weight. Then, carcasses were maintained $24 \mathrm{~h}$ at $5^{\circ} \mathrm{C}$, and was recorded cold carcass weight. Average daily live weight gain was affected by treatments, with slaughter age as covariable. Higher performance values were observed for lambs fed rations with 3.0 Mcal ME. Considering carcasses traits, there was no effect of treatments. It was concluded that 3.0 Mcal ME was the most indicated for rations of Suffolk lambs fed and finished in creep feeding.
\end{abstract}

Key Words: creep feeding, sheep growth, supplementation

\section{Introdução}

Inúmeras modificações vêm ocorrendo na ovinocultura nacional, visando atender as necessidades do mercado, principalmente devido à competição com produtos de origem animal, provenientes dos demais países pertencentes ao MERCOSUL, uma vez que estes levam vantagens, pois as condições climáticas e de fertilidade do solo favorecem o abate de cordeiros precoces, com boa qualidade de carne
(Pereira \& Santos, 2001).

O mercado consumidor brasileiro paulatinamente vem aumentando a aceitação pela carne ovina. Porém, a oferta do cordeiro ainda é restrita e estacional, necessitando-se de melhoria nas condições de abate, além da disponibilização de cordeiros jovens, objetivando a mudança da concepção da população sobre a carne desta espécie (Silva Sobrinho, 2001).

Nos últimos anos, têm-se buscado inovações, com sistemas intensivos para produção de ovinos.

\footnotetext{
1 Parte da Tese de Doutorado do primeiro autor, projeto financiado pela Universidade de Marília (UNIMAR) e FAPESP (98/07014-5)

2 Professor de Ovinocultura da FCA-UNIMAR, CP.504, CEP 17.525-902, Marília-SP. E.mail: cgarcia-ca@unimar.br

3 Professor do Departamento de Melhoramento e Nutrição Animal, FMVZ-UNESP, Campus de Botucatu-SP. E.mail: ciniro@fca.unesp.br ${ }^{4}$ Professora da UFPR, Departamento de Zootecnia, Curitiba-PR. E.mail: alda.Igm@ufpr.br

5 Professora do CCA, UNIOESTE, Mal. Cândido Rondon, PR. E.mail: abbado@unioeste.br

6 Professor do Departamento de Bioestatística - IB/ UNESP - Botucatu - SP.
} 
Para obtenção de bons resultados, devem-se melhorar os índices zootécnicos, principalmente com a redução na idade de abate dos cordeiros, sendo o creep feeding (fornecimento de ração em comedouro seletivo) uma opção nesse contexto (Johnston, 1992; Santra \& Karim, 1999), com grande importância para o aumento da produtividade. Este sistema de alimentação tem sido cada vez mais utilizado por técnicos que atuam na ovinocultura (Wilson et al., 1971; Ockerman et al., 1982; Bortoletto et al., 1997; Pereira \& Santos, 2001; Villas Bôas, 2001), objetivando maximização dos índices zootécnicos. Em alguns trabalhos já realizados (Neres et al., 2001b; Villas Bôas, 2001), o peso de abate recomendado economicamente para cordeiros no mercado do Estado de São Paulo (Macedo, 1998; Siqueira et al., 2001) foi atingido sem a necessidade de confinamento. Para tanto, foi necessário estabelecer estratégias de suplementação alimentar.

A energia é o constituinte mais limitante na produção de ovinos, atrasando principalmente o ganho em peso (Mahgoub et al., 2000), com conseqüente aumento na idade à puberdade ou idade de abate, além de resultar em menor resistência as endoparasitoses. Porém, quando fornecida em excesso, pode aumentar a deposição de gordura na carcaça (Susin, 1996).

Os cordeiros lactentes têm o ritmo de crescimento acelerado, obedecendo à seqüência de deposição de tecido ósseo, muscular e finalmente o tecido adiposo (Reis et al., 2001). Geralmente, o leite e o pasto não atendem às exigências dos cordeiros nesta fase, principalmente quando a raça criada for de carne e com ciclo reprodutivo poliéstrico estacional, concentrando as parições em julho e agosto, época de baixa disponibilidade de forragem. A recomendação nutricional do NRC (1985) para cordeiros com potencial de crescimento moderado, pesando entre 10 a $30 \mathrm{~kg}$ (média de $20 \mathrm{~kg}$ ) é de cerca de $17 \%$ de PB e 2,8 Mcal EM. Porém, as condições ambientais, o manejo e a genótipo são diferentes nos ambientes tropicais, podendo gerar alterações na demanda por nutrientes.

Além do genótipo e qualidade da dieta, os diversos sistemas de produção também têm influenciado as características das carcaças dos ovinos, além do desempenho (Neres, 2000). Portanto, novos estudos são necessários, objetivando a antecipação da idade de abate para raças tipo carne, principalmente para a terminação de cordeiros ainda no desmame (Garcia et al., 2001), minimizando custos com alimentação, mão-de-obra e instalações, seja em confinamento como em pastagem (Siqueira et al., 2001).

A conformação e a composição da carcaça devem ser levadas em consideração, quando se propõem sistemas de alimentação suplementar, visando acelerar o ritmo de crescimento de animais jovens, uma vez que aquelas características podem influenciarno rendimento e a qualidade da carne (Barros \& Simplício, 2001).

Objetivou-se com este trabalho estudar o efeito dos níveis de energia da ração suplementar sobre o desempenho e as características das carcaças de cordeiros Suffolk alimentados e terminados em creep feeding.

\section{Material e Métodos}

O experimento foi realizado no Setor de Ovinocultura da Fazenda Experimental "Marcelo Mesquita Serva", pertencente à Faculdade de Ciências Agrárias da Universidade de Marília (UNIMAR), no município de Marília, SP. O delineamento experimental foi inteiramente casualizado com três tratamentos (2,6; 2,8 e 3,0 Mcal EM/kg MS da ração) e doze repetições. Foram utilizados 36 cordeiros inteiros, mestiços Suffolk, oriundos de parto simples e alimentados e terminados em creep feeding.

$\mathrm{Na}$ Tabela 1, encontram-se a composição percentual das rações e na Tabela 2 , os resultados da análise química dos ingredientes e das rações experimentais, segundo a metodologia descrita por Silva (1981). As rações isoprotéicas foram formuladas para conter $18,5 \%$ de PB.

No terço final de gestação e durante todo o período experimental as ovelhas foram suplementadas diariamente com feno de Tifton-85 (Cynodon spp.) à vontade, além do concentrado $(16,17 \%$ PB e $77 \%$ NDT), em uma área exclusiva para as mesmas, constituída de grão de milho moído, farelo de trigo e farelo de soja, fornecendo $1 \%$ do peso vivo, com base na matéria seca, visando atender as exigências nutricionais dessa fase (NRC, 1985).

Após o parto, as ovelhas foram distribuídas aleatoriamente, com seus respectivos cordeiros, em piquetes de estrela branca (Cynodon plectostachyus). Em virtude da concentração de parições no período do inverno, quando a pastagem apresentava pequena disponibilidade de matéria seca e baixa qualidade, os lotes foram submetidos em sistema de pastejo alternado.

Semanalmente as ovelhas foram ordenhadas, para 
Tabela 1 - Composição percentual das rações experimentais, com três níveis de energia em Mcal de $E M / k g$ MS

Table 1 - Percent composition of the ingredients of experimental rations, with three energy levels in Mcal $M E / k g D M$

\begin{tabular}{|c|c|c|c|}
\hline \multirow[b]{2}{*}{$\begin{array}{l}\text { Ingrediente } \\
\text { Ingredient }\end{array}$} & \multicolumn{3}{|c|}{$\begin{array}{c}\text { Nível de energia (Mcal EM/kg MS) } \\
\text { Energy level (Mcal ME/kg DM) }\end{array}$} \\
\hline & 2,6 & 2,8 & 3,0 \\
\hline $\begin{array}{l}\text { Feno de alfafa } \\
\text { Alfalfahay }\end{array}$ & 15,00 & 15,00 & 15,00 \\
\hline $\begin{array}{l}\text { Farelo de soja } \\
\text { Soybean meal }\end{array}$ & 25,00 & 24,00 & 23,50 \\
\hline $\begin{array}{l}\text { Milho moído } \\
\text { Ground corn }\end{array}$ & 43,50 & 51,50 & 56,00 \\
\hline $\begin{array}{l}\text { Casca de arroz } \\
\text { Rice hulls }\end{array}$ & 15,00 & 8,00 & 3,00 \\
\hline $\begin{array}{l}\text { Sal mineral } \\
\text { Mineral salt }\end{array}$ & 1,00 & 1,00 & 1,00 \\
\hline $\begin{array}{l}\text { Óleo vegetal } \\
\text { Vegetable oil }\end{array}$ & 0,50 & 0,50 & 1,50 \\
\hline
\end{tabular}

obtenção da curva de lactação. Para tal, aplicava-se dois mililitros de ocitocina intramuscular e realizavase, em seguida, a ordenha manual, até ocorrer o esvaziamento do úbere. Após o período de quatro horas, no qual as ovelhas permaneciam separadas dos cordeiros, repetia-se o procedimento, segundo metodologia de Neto \& Cunha (1994). A estimativa da produção de leite foi realizada multiplicando-se o valor obtido por seis ( $4 \mathrm{~h} \mathrm{x} 6=24$ horas).

Logo após o nascimento, os cordeiros foram pesados e numerados. Na primeira semana de vida, os mesmos foram fechados na área cercada do creep feeding, por 4 horas diárias, para adaptação às instalações e para o contato inicial com o alimento sólido. $\mathrm{O}$ acesso à ração foi ad libitum, com pesagens diárias das quantidades fornecidas e das sobras, para o cálculo do consumo médio diário dos cordeiros por tratamento.

Aos 14 dias de idade, os cordeiros receberam a 1a dose de vacina contra Clostridioses (Polivalente Sintoxan $\left.{ }^{\circledR}\right)$, com reforço após 30 dias. Semanalmente foi realizada a coleta de fezes, diretamente da ampola retal dos cordeiros e ovelhas, objetivando o monitoramento das infecções parasitárias, pela contagem do número de ovos por grama de fezes (OPG), segundo metodologia de Matos \& Matos (1988). A desverminação é recomendada toda vez que a contagem atinge acima de 500 OPG.

A pesagem dos cordeiros era realizada a cada 14 dias, no período da manhã, para determinação do ganho médio de peso diário. Quando o peso vivo final aproximava-se dos $31 \mathrm{~kg}$, preestabelecidos inicialmente, calculava-se o ganho médio no último intervalo de 14 dias e estimava-se a data de abate. Na véspera da data prevista, os animais eram pesados e separados

Tabela 2 - Composição química dos ingredientes e das rações experimentais, com três níveis de energia Table 2 - Chemical composition of ingredients and experimental rations with three energy levels

\begin{tabular}{|c|c|c|c|c|c|c|c|c|}
\hline $\begin{array}{l}\text { Ingrediente } \\
\text { Ingredient }\end{array}$ & $\begin{array}{l}\text { MS } \\
D M\end{array}$ & $\begin{array}{l}\mathrm{PB} \\
C P\end{array}$ & $\begin{array}{l}\mathrm{EE} \\
E E\end{array}$ & $\begin{array}{l}\mathrm{MM} \\
M M\end{array}$ & $\begin{array}{l}\text { FDN } \\
N D F\end{array}$ & $\begin{array}{l}\text { FDA } \\
A D F\end{array}$ & $\begin{array}{l}\text { Lignina } \\
\text { Lignin }\end{array}$ & $\begin{array}{l}\text { Celulose } \\
\text { Celullose }\end{array}$ \\
\hline $\begin{array}{l}\text { FA } \\
A F\end{array}$ & 87,83 & 19,13 & 3,35 & 8,40 & 59,63 & 46,10 & 14,63 & 32,06 \\
\hline $\begin{array}{l}\text { F S } \\
S M\end{array}$ & 87,29 & 46,53 & 3,57 & 6,44 & 11,85 & 10,65 & 2,20 & 8,00 \\
\hline $\begin{array}{l}\mathrm{M} \mathrm{M} \\
G C\end{array}$ & 87,15 & 8,06 & 6,21 & 1,63 & 9,48 & 2,89 & 0,73 & 2,10 \\
\hline $\begin{array}{l}\mathrm{C} \mathrm{A} \\
R H\end{array}$ & 92,19 & 2,16 & 0,97 & 18,58 & 85,26 & 73,15 & 8,89 & 44,17 \\
\hline
\end{tabular}

\section{Rações}

\section{Rations}

Nível de energia (Mcal EM/kg MS)

Energy level (Mcal ME/kg DM)

\begin{tabular}{lllllllll}
2,6 & 89,72 & 18,52 & 3,70 & 7,46 & 24,01 & 19,44 & 3,85 & 12,43 \\
2,8 & 89,60 & 18,41 & 4,36 & 6,76 & 22,47 & 14,44 & 2,97 & 9,65 \\
3,0 & 89,34 & 18,45 & 5,20 & 5,88 & 18,21 & 9,96 & 2,46 & 6,78 \\
\hline
\end{tabular}

MS: matéria seca; PB: proteína bruta; EE: extrato etéreo; MM: matéria mineral; FB: fibra bruta; ENN: extrativo não nitrogenado; EM: energia metabolizável (Mcal); FDN: fibra em detergente neutro; FDA: fibra em detergente ácido. FA: feno de alfafa; MM; milho moído; FS: farelo de soja; CA: casca de arroz.

DM: dry matter; CP: crude protein; EE: ether extract; MM: mineral matter; ME: metabolizable energy; NDF: neutral detergent fiber; ADF: acid detergent fiber. AF: alfalfa hay; SM: soybean meal; GC: ground corn RH: rice hulls. 
das mães por volta das $17 \mathrm{~h}$, permanecendo com dieta hídrica exclusiva, por aproximadamente 16 horas. No dia seguinte, registrava-se o peso vivo ao abate (PVA) e os animais eram abatidos.

Após o abate, os animais foram eviscerados e o aparelho gastrintestinal foi esvaziado, para obtenção do peso de corpo vazio ( $\mathrm{PCV}=$ peso vivo ao abate - conteúdo gastrintestinal). Terminada a evisceração, registrou-se o peso da carcaça quente (PCQ), sendo as mesmas levadas para câmara de refrigeração a $5^{\circ} \mathrm{C}$, permanecendo por 24 horas penduradas pelas articulações tarso metatarsianas. Ao final desse período, obteve-se o peso da carcaça fria (PCF), calculando-se a partir deste, a porcentagem de perda de peso por resfriamento $[\mathrm{PR} \%=(\mathrm{PCQ}-\mathrm{PCF}) / \mathrm{PCQ} \times 100]$. As seguintes variáveis foram obtidas por cálculo: rendimento da carcaça quente $(\mathrm{RCQ} \%=\mathrm{PCQ} / \mathrm{PVA} \times 100)$, rendimento comercial ou rendimento da carcaça fria $(\mathrm{RCF} \%=\mathrm{PCF} / \mathrm{PVA} \times 100)$ e o rendimento verdadeiro $(\mathrm{RV} \%=\mathrm{PCQ} / \mathrm{PCV} \times 100)$.

Para o ganho médio de peso diário efetuou-se a análise de variância, segundo modelo matemático incluindo o efeito fixo da ração e a covariável idade de abate. Efetuou-se estudo das regressões polinomiais, segundo os três níveis de energia. Para as demais variáveis foi realizada a análise de variância, segundo modelo matemático, que incluiu somente o efeito fixo da ração e o estudo das regressões polinomiais, em função dos três níveis de energia. As análises foram realizadas pelo procedimento GLM do SAS (1985).

\section{Resultados e Discussão}

Ocorreu efeito significativo $(\mathrm{P}<0,05)$ dos tratamentos somente para o ganho médio de peso diário, considerando-se o efeito fixo da ração $(\mathrm{R})$ e a covariável idade de abate (IA), em função dos três níveis de energia. Na Tabela 3, estão os resultados de peso ao nascer, ganho médio de peso diário e idade de abate dos cordeiros.

Na Figura 1 apresenta-se a regressão polinomial, que obedeceu o modelo quadrático ( $\mathrm{Y}=-2.375,48$ $\left.5,67 x(\mathrm{IA})+2.242,39 \mathrm{x}(\mathrm{R})-399,17 \mathrm{x}(\mathrm{R})^{2}\right)$. A ração que promoveu o ganho máximo de peso diário foi a que possuía 3,0 Mcal Em/kg MS.

Os bons pesos ao nascer foram devido à boa condição corporal das ovelhas suplementadas no terço final de gestação, além de que machos apresen-

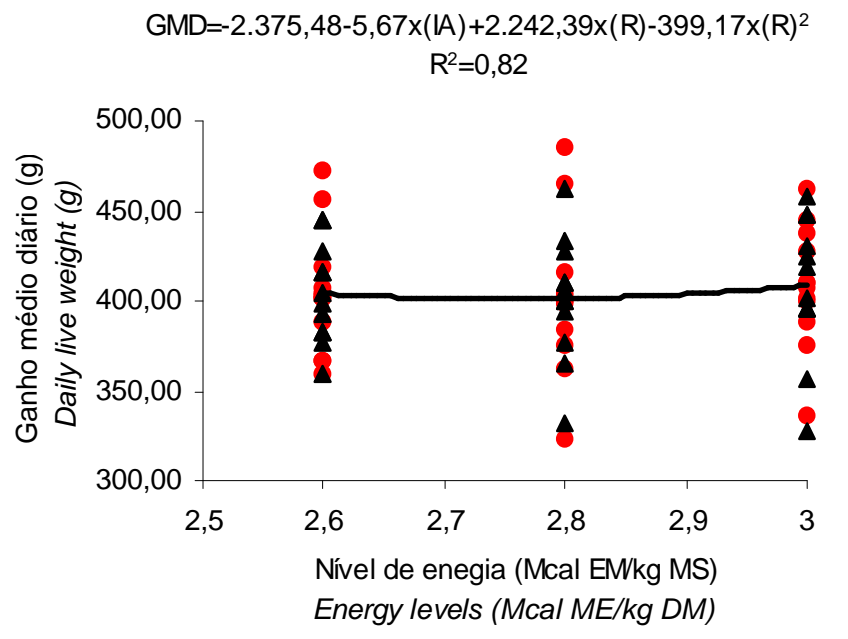

Figura 1 - Ganho médio diário (g) dos cordeiros, em função dos níveis de energia na dieta (observado $(\bullet)$ e estimado $(\bullet))$.

Figure 1 - Daily live weight gain $(\mathrm{g})$ of lambs according to energy levels in diets (observed (๑) and estimated $(\cdot))$.

tarem maior peso ao nascimento e raças de carne parirem cordeiros mais pesados, concordando com Motta (2000).

Os resultados de desempenho e idade de abate foram próximos aos obtidos por Neres et al. (2001a) que usaram cordeiros inteiros Suffolk, alimentados em creep feeding em dois experimentos, por dois anos consecutivos. No primeiro ano as rações possuíam média de 20,90\%PB e 2,96 EM e foi necessário o confinamento para terminação após o desmame; os cordeiros apresentaram ganho médio de peso diário de $371 \mathrm{~g}$, sendo inferior aos do presente estudo em $8,31 \%$. No segundo ano, os autores testaram rações farelada e peletizada, ambas com 17,99 \%PB e 2,96 EM; obtiveram superioridade em desempenho para os cordeiros alimentados com a ração peletizada (393 g/dia), com idade média ao abate de 60 dias. Os animais alimentados com ração farelada apresentaram ganho de $369 \mathrm{~g} /$ dia e foram abatidos com idade de 64 dias; ambos grupos foram abatidos com $28 \mathrm{~kg}$ de peso vivo final no desmame. Apesar de o peso de abate padronizado pelos pesquisadores acima citados ter sido inferior $(30,79 \mathrm{~kg})$, os animais apresentaram praticamente a mesma idade média de abate $(63,22$ dias), confirmando o maior ganho de peso diário dos animais do presente estudo, com média de 403,86; 401,39 e $408,57 \mathrm{~g}$, respectivamente, para os três níveis de energia. 
Tabela 3 - Médias do peso ao nascer, ganho médio diário e idade de abate dos cordeiros alimentados com três níveis de energia e seus coeficientes de variação (CV\%)

Table 3 - Mean of birth weight, daily weight gain and slaughter age of lambs fed with three energy levels and coefficients of variation (CV\%)

\begin{tabular}{|c|c|c|c|c|}
\hline \multirow[b]{2}{*}{$\begin{array}{l}\text { Variável } \\
\text { Variable }\end{array}$} & \multicolumn{4}{|c|}{$\begin{array}{c}\text { Nível de energia (Mcal EM/kg MS) } \\
\text { Energy level (Mcal ME/kg DM) }\end{array}$} \\
\hline & 2,6 & 2,8 & 3,0 & $\mathrm{CV}(\%)$ \\
\hline $\begin{array}{l}\text { Peso ao nascer }(\mathrm{kg}) \\
\text { Birth weight }(\mathrm{kg}) \\
\text { Ganho médio diário (g/dia) }\end{array}$ & 5,99 & 5,17 & 5,46 & 11,50 \\
\hline $\begin{array}{l}\text { Daily weight gain (g/day) } \\
\text { Idade de abate (dias) }\end{array}$ & $403,86^{*}$ & $401,39^{*}$ & $408,57^{*}$ & 3,98 \\
\hline Slaughter age (days) & 62,17 & 65,67 & 61,83 & 9,26 \\
\hline
\end{tabular}

* Significativo pelo teste $\mathrm{F}$ a $5 \%$ de probabilidade (Significant at $5 \%$ by $\mathrm{F}$ test).

Pereira \& Santos (2001) adotaram o mesmo sistema de terminação, com cordeiros das raças Ile de France, Hampshire Down e Suffolk, todas com aptidão para produção de carne, abatidos com peso vivo médio de $37,57 \mathrm{~kg}$ e obtiveram média geral de ganho de peso diário de $410 \mathrm{~g}$, com valores próximos aos obtidos neste estudo.

Os ganhos médios de peso diário foram superiores aos dos cordeiros criados em creep feeding encontrados por Wilson et al. (1971), ao suplementarem três grupos de ovelhas em lactação, com diferentes níveis de energia. O primeiro grupo de ovelhas recebeu dieta com $25 \%$ abaixo da exigência preconizada pelo NRC (1968); o segundo foi alimentado segundo a recomendação de exigência e o terceiro recebeu dieta com $25 \%$ acima da recomendação. Estes autores estudaram cordeiros mestiços Merino x Dorset x Suffolk, com fornecimento de ração em creep feeding somente a partir dos 21 dias de idade, com mesma dieta para os três grupos de cordeiros, apresentando 14,6\% PB e 3,3 kcal/kg ED (2,7 Mcal EM). Os valores de peso vivo final dos cordeiros obtidos por esses pesquisadores, que mais se aproximaram dos resultados do presente trabalho, foram do lote cujas ovelhas foram suplementadas com alto nível de energia, $25 \%$ acima das exigências recomendadas pelo NRC (1968); provavelmente, isso tenha ocorrido devido às ovelhas terem produzido maiores quantidades de leite $(1.408 \mathrm{~g} / \mathrm{dia})$, e assim, conseqüentemente os cordeiros apresentaram superioridade em desempenho ( $274 \mathrm{~g} / \mathrm{dia})$, com peso médio de $26,3 \mathrm{~kg}$ ao final dos 77 dias.

Otto et al. (1994) compararam o efeito da idade ao desmame de 45 e 60 dias no desenvolvimento de cordeiros mestiços Suffolk, com acesso ao creep feeding, recebendo ração com $14 \%$ de $\mathrm{PB}$ e $60 \%$ NDT, além de pastagem de inverno. Não houve diferença $(\mathrm{P}>0,05)$ para ganho de peso dos cordeiros até os 120 dias de idade, com ganho médio de peso diário de 190 e $182 \mathrm{~g}$, para os desmamados aos 45 dias e 60 dias, respectivamente. O desmame aos 45 dias não prejudicou o desenvolvimento dos cordeiros, quando comparados com aqueles desmamados aos 60 dias. A pesquisa não tinha como objetivo abater os cordeiros no desmame; por esse motivo, recomendaram o desmame aos 45 dias.

Villas Bôas (2001) usou cordeiros inteiros mestiços Hampshire Down, desmamados em diferentes idades ( 34 e 62 dias) e alimentados com mesma dieta em creep feeding nesta fase. Os cordeiros com peso abaixo de $28,63 \mathrm{~kg}$ no desmame eram confinados. $\mathrm{O}$ referido autor verificou superioridade para os cordeiros desmamados aos 62 dias, filhos das ovelhas não suplementadas, com ganho médio diário de $389 \mathrm{~g}$ e idade de aproximada de 61 dias, valores semelhantes aos obtidos no presente trabalho.

Quando se trabalha com ovinos de raças com elevado ritmo de crescimento em sistemas intensivos de produção, obtém-se redução na idade de abate e melhor eficiência alimentar, reduzindo os gastos com alimentação, principal componente do custo total de produção (Siqueira et al., 2001).

A ingestão de leite tem papel fundamental no comportamento de ganho de peso de cordeiros, criados em sistema de creep feeding (Villas Bôas, 2001). Além disso, cabe ressaltar que a raça e o genótipo dos ovinos podem afetar a qualidade do leite produzido. Segundo Bencini \& Pulina (1997), existe correlação negativa entre a produção e a composição do leite. Animais que produzem mais leite, geralmente 
possuem menor concentração de gordura e proteína, embora quantitativamente os valores sejam elevados, considerando a maior produção. Ainda os mesmos autores afirmaram que a raça Suffolk apresenta em média $5,8 \%$ PB e $6,6 \%$ de gordura no leite.

Estudo de diferentes dietas no creep feeding foi conduzido por Johnston (1992), usando-se cordeiros cruzas das raças Targhee x Hamphire Down, com distintas idades de desmame. Em um dos ensaios realizados, o autor avaliou o consumo de leite in natura, além da ração no creep feeding a partir do terceiro dia. Os animais desmamados aos 42 dias de idade revelaram ganho médio de peso diário de 270 $\mathrm{g}$, desempenho este cerca de $33 \%$ menor à média geral encontrada nesse trabalho $(404,6 \mathrm{~g})$ com a raça Suffolk.

Na Figura 2 encontra-se a curva de lactação das ovelhas. A estimativa da produção média de leite das ovelhas dos três grupos (2,6; 2,8 e 3,0 Mcal EM), durante o período foi de $2.035,5 ; 1.716,0$ e $1.614,25 \mathrm{~g} / \mathrm{dia}$, respectivamente. Observa-se, então, que à medida que aumentou a concentração energética das rações diminuiu a produção de leite das ovelhas. Provavelmente tenha ocorrido maior freqüência de mamadas dos cordeiros que foram suplementados com menor concentração energética na ração, visando atender às exigências nutricionais dos mesmos, o que deve ter resultado em maior secreção láctea das mães.

A produção de leite estimada está abaixo da observada por Hadjipanayiotou (1995), para ovelhas da raça leiteira Chios, apresentando média de $2.450 \mathrm{~g} / \mathrm{dia}$; e superiores as médias encontradas por Neto \& Cunha (1994) para ovelhas da raça Santa Inês, em criação extensiva sem suplementação alimentar, com média geral de $668,8 \mathrm{~g}$ de leite por dia. Os dados obtidos com a raça Suffolk, aqui avaliada, apresentam similaridade às produções médias diárias de borregas e ovelhas da raça Texel, estudadas por Motta (2000), nesse caso suplementadas com silagem de milho, com seus cordeiros alimentados ou não em creep feeding até a quarta semana de vida. As médias para borregas e ovelhas, com cordeiros recebendo ração no creep feeding foi de 1.528,0 e 1.630,0 $\mathrm{g} /$ leite/dia, respectivamente; as borregas e ovelhas cujos cordeiros não receberam ração no comedouro seletivo produziram 1.620,0 e 1.410,0 g/leite/dia, respectivamente. Observa-se que a produção de leite das ovelhas Texel (1.520 g de leite/dia) foi pouco inferior à média estimada das ovelhas Suffolk estuda- das nesse ensaio (1.789 $\mathrm{g}$ de leite/dia).

O pico da lactação das ovelhas ocorreu entre a 3a e a 4a semanas após o parto, concordando com Bencini \& Pulina (1997) e tendo grande contribuição para o ganho de peso dos cordeiros nesta fase, o que pode ser confirmado por Motta (2000) que verificou correlação de $64 \%$ entre a produção de leite das mães e o ganho de peso das crias nas primeiras três semanas.

No caso dos cordeiros Suffolk do presente trabalho, após esta fase, os mesmos consumiram mais ração oferecida no creep feeding, devido ao aumento das suas exigências nutricionais, evidenciando desta maneira que o leite não é suficiente para atendê-las. A média de consumo de ração no creep feeding no período foi de 387; 459 e $439 \mathrm{~g} / \mathrm{dia}$, respectivamente, para 2,6; 2,8 e 3,0 Mcal; sendo estes valores próximos aos observados por Neres et al. (2001a), com consumo médio de $434 \mathrm{~g} / \mathrm{dia}$, para cordeiros Suffolk alimentados em creep feeding.

$\mathrm{Na}$ Tabela 4, encontram-se os resultados das características das carcaças segundo os níveis de energia da dieta, não observando-se efeito $(\mathrm{P}>0,05)$ para as variáveis estudadas.

Os resultados para o rendimento de carcaça quente e fria, e perda no resfriamento, deste trabalho estão próximos aos encontrados por Neres et al. (2001b), para cordeiros abatidos com peso vivo de 26 e $28 \mathrm{~kg}$, com rendimento de carcaça quente $53,74 \mathrm{e}$ $52,48 \%$, rendimento comercial de 52,16 e $50,94 \%$ e perdas no resfriamento de 2,92 e $2,96 \%$, respectivamente. Estes valores apresentam grande similaridade aos observados por Villas Bôas (2001), para cordeiros desmamados aos 62 dias, com ovelhas suplementadas ou não, apresentando rendimento médio

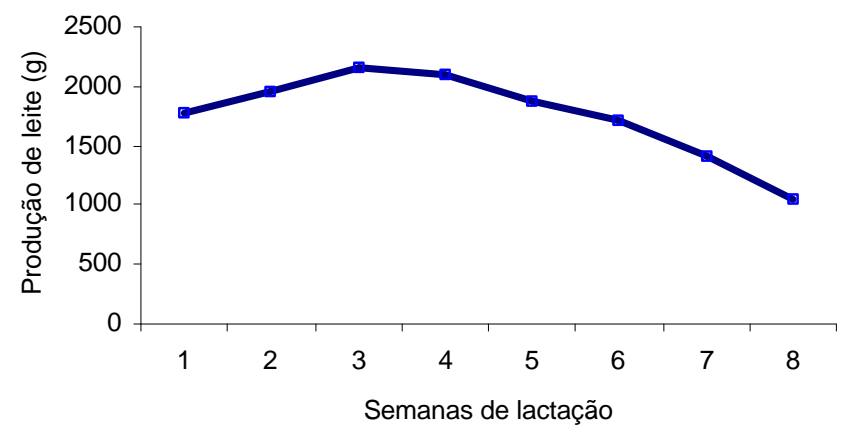

Figura 2 - Curva média de lactação das ovelhas Suffolk. Figure 2 - Mean lactation of Suffolk dams. 
de carcaça de 50,4\%, com idade média de abate de 65 dias. Entretanto, os cordeiros desmamados com 34 dias, que, em seguida, foram confinados para atingir o peso de abate, apresentaram rendimento médio de carcaça de 45,69\%, com idade média de abate de 73,22 dias, sendo valores inferiores aos verificados no presente trabalho.

O rendimento médio de carcaça quente encontrado nesse ensaio (52,76\%) foi superior em $17,17 \%$ ao observado por Pereira \& Santos (2001) que usaram cordeiros puros e mestiços Suffolk, alimentados com ração em creep feeding até o desmame (60 dias) e confinados até atingirem o peso de abate de $38,0 \mathrm{~kg}$, com idade média de 85 dias, verificando rendimento de carcaça de $43,7 \%$.

Dessa maneira, tomando-se como base os dois trabalhos citados anteriormente, pode-se deduzir que, quando os cordeiros foram desmamados, seja de maneira precoce (34 dias) ou semiprecoce (60 dias) e em seguida permanecendo em confinamento, o rúmen atingiu sua plenitude funcional, aumentando o espaço físico com o consumo de alimentos sólidos, elevando-se o volume do sistema digestório como um todo. Conseqüentemente, diminuiu o rendimento de carcaça, o que não foi observado no presente estudo, para cordeiros terminados em creep feeding.

Mahgoub et al. (2000) usaram cordeiros Omani, raça adaptada em clima quente, com acesso livre ao creep feeding na fase pré-desmama, avaliaram o efeito da densidade energética da dieta de confinamento $(2,46 ; 2,83$ e 3,19 Mcal EM/kg MS) na fase pós-desmama. Os animais foram abatidos com peso médio de abate de $30,66 \mathrm{~kg}$, com peso e rendimentos da carcaça quente de $14,32 \mathrm{~kg}$ e $52,96 \%$, respectivamente, sendo valores próximos aos obtidos no presente trabalho. Porém, destaca-se que os cordeiros Omani atingiram este peso de abate aos 194 dias, ou seja, aproximadamente seis meses de idade, enquanto que os cordeiros Suffolk, com apenas dois meses apresentaram os valores discutidos. Isso se faz muito interessante no ponto de vista econômico, pela enorme redução no tempo de alimentação.

Preziuso et al. (1999), usando diferentes fontes de energia (lipídios e carboidratos) para cordeiros na fase pós desmame (45 dias), até atingirem o peso vivo ao abate de $32,95 \mathrm{~kg}$ com 105 dias de idade, observaram rendimento médio de carcaça de $50,22 \%$.

Quando se comparam cordeiros alimentados em creep feeding com animais desmamados convencio- nalmente, a diferença de idade de abate é bastante expressiva. Macedo (1998) trabalhou com cordeiros Corriedale e suas cruzas com Hampshire Down e Bergamácia, desmamados aos 60 dias, sendo posteriormente divididos em dois grupos, um permanecendo em pasto de coast cross (Cynodon dactylon) e outro confinado. A idade média de abate foi de $258 \mathrm{e}$ 219 dias, o peso da carcaça quente de 11,94 e 13,37 kg, a carcaça fria de 11,45 e $12,92 \mathrm{~kg}$, o rendimento verdadeiro de 46,95 e $49,70 \%$ e o rendimento de carcaça fria de 38,27 e $42,59 \%$, respectivamente. Os cordeiros confinados apresentaram resultados superiores $(\mathrm{P}<0,05)$ aos terminados em pastejo. Quando se comparam esses dados dos animais confinados aos obtidos no presente estudo, verifica-se que a idade de abate foi bem mais tardia (cerca de cinco meses) e os resultados de carcaça inferiores. Observa-se, na Tabela 4, que os cordeiros Suffolk em creep feeding apresentaram valores médios de $15,12 \mathrm{~kg}$ para o peso da carcaça quente, $14,61 \mathrm{~kg}$ para o peso de carcaça fria, $51,11 \%$ para o rendimento de carcaça fria, $57,80 \%$ para o rendimento verdadeiro, confirmando o benefício deste sistema de produção para as raças tipo carne.

Oliveira et al. (2001) trabalharam com cordeiros Santa Inês, desmamados aos 99 dias de idade e $20 \mathrm{~kg}$ de peso vivo, terminados em pastejo rotacionado de Tifton-85 (Cynodon sp.). Um dos grupos de cordeiros permaneceu exclusivamente em pastejo e o outro além do pasto recebeu suplementação concentrada (16\% PB e $70 \%$ NDT), na base de $1 \%$ do peso vivo. Os cordeiros foram abatidos, quando atingiram 178 dias de idade, apresentando peso vivo de 30,73 e $32,70 \mathrm{~kg}$, respectivamente. Estes pesquisadores não observaram diferença $(\mathrm{P}>0,05)$ para as variáveis estudadas. Entretanto, a idade para atingir o peso de abate foi três vezes superior à obtida na presente pesquisa (63 dias), confirmando que a raça Suffolk tem resposta bastante acentuada em desempenho e rendimento, quando a dieta fornecida atende sua exigência nutricional.

Objetivando comparar a recria de cordeiros (as) de diferentes genótipos, desmamados aos 60 dias e permanecendo em confinamento e/ou pastagem por período de 91 dias, Siqueira et al. (1993) observaram superioridade no ganho de peso para cordeiros confinados (153 g/dia); enquanto que em pastejo apresentaram ganho de $82 \mathrm{~g} / \mathrm{dia}$, inclusive com mortalidade de $16,13 \%$ devido à endoparasitose, que não foi observada para os animais confinados. As médias de 
Tabela 4 - Médias das características das carcaças dos cordeiros alimentados com três níveis de energia e seus coeficientes de variação (CV\%)

Table 4 - Mean of carcasses traits of lambs fed with three energy levels and coefficients of variation (CV\%)

\begin{tabular}{|c|c|c|c|c|}
\hline \multirow[b]{2}{*}{$\begin{array}{l}\text { Variável } \\
\text { Variable }\end{array}$} & \multicolumn{4}{|c|}{$\begin{array}{l}\text { Nível de energia (Mcal EM/kg MS) } \\
\text { Energy level (Mcal ME/kg DM) }\end{array}$} \\
\hline & 2,6 & 2,8 & 3,0 & $\mathrm{CV}(\%)$ \\
\hline $\begin{array}{l}\text { Peso vivo final }(\mathrm{kg}) \\
\text { Final live weight }(\mathrm{kg})\end{array}$ & 30,94 & 31,09 & 30,34 & 2,73 \\
\hline $\begin{array}{l}\text { Peso vivo de abate }(\mathrm{kg}) \\
\text { Slaughter weight }(\mathrm{kg})\end{array}$ & 28,55 & 28,44 & 28,82 & 3,60 \\
\hline $\begin{array}{l}\text { Peso de corpo vazio }(\mathrm{kg}) \\
\text { Empty live weight }(\mathrm{kg})\end{array}$ & 26,16 & 25,84 & 26,48 & 3,99 \\
\hline $\begin{array}{l}\text { Peso da carcaça quente }(\mathrm{kg}) \\
\text { Hot carcass weight }(\mathrm{kg})\end{array}$ & 15,00 & 15,12 & 15,23 & 4,77 \\
\hline $\begin{array}{l}\text { Peso da carcaça fria }(\mathrm{kg}) \\
\text { Cool carcass weight }(\mathrm{kg})\end{array}$ & 14,56 & 14,58 & 14,71 & 5,03 \\
\hline $\begin{array}{l}\text { Rendimento de carcaça quente }(\%) \\
\text { Hot carcass dressing-out }(\%)\end{array}$ & 52,21 & 53,21 & 52,87 & 4,43 \\
\hline $\begin{array}{l}\text { Rendimento da carcaça fria }(\%) \\
\text { Cool carcass dressing-out }(\%)\end{array}$ & 50,97 & 51,32 & 51,06 & 4,50 \\
\hline $\begin{array}{l}\text { Rendimento verdadeiro (\%) } \\
\text { Biological dressing-out (\%) }\end{array}$ & 57,31 & 58,60 & 57,50 & 3,32 \\
\hline $\begin{array}{l}\text { Perda no resfriamento }(\%) \\
\text { Cooling losses }(\%)\end{array}$ & 2,88 & 3,43 & 3,38 & 47,77 \\
\hline
\end{tabular}

peso vivo aos 151 dias de idade foram de 23,94 e $16,81 \mathrm{~kg}$ para o grupo em confinamento e pastagem, respectivamente. Estes resultados confirmam que cordeiros bem nutridos resistem mais às endoparasitoses. No presente estudo, o monitoramento semanal da verminose em nenhum momento apresentou médias de ovos por grama (OPG) de fezes acima de 500, não necessitando, portanto, de desverminação ao longo do período experimental. Embora a infecção parasitária não tenha sido o objetivo deste estudo, isso também pôde ser considerado como ponto favorável à adoção da alimentação e terminação de cordeiros em creep feeding.

\section{Conclusões}

Para o desempenho animal, o melhor resultado foi para os cordeiros Suffolk alimentados e terminados em creep feeding com 3,0 Mcal EM na ração. Para as características da carcaça não houve efeito dos níveis de energia da ração, indicando que 3,0 Mcal pode ser recomendado para esta categoria animal.

O fornecimento de ração em creep feeding para cordeiros lactentes foi essencial para melhoria dos índices zootécnicos, principalmente pela redução da idade de abate.

O creep feeding pode ser considerado técnica indicada para a terminação de cordeiros, mesmo para aqueles ovinocultores que não tenham raças especializadas para carne, pois o ganho de peso adicional nesta fase pode proporcionar a redução da idade de abate, independentemente do sistema de terminação, contribuindo para o avanço da ovinocultura nacional.

\section{Literatura Citada}

BARROS, N.N.; SIMPLÍ́CIO, A.A. Produção intensiva de ovinos de corte: perspectivas e cruzamentos. In: SIMPÓSIO MINEIRO DE OVINOCULTURA, 1., 2001. Anais...Lavras: Universidade Federal de Lavras, 2001. p.21-49.

BENCINI, R.; PULINA, G. The quality of sheep milk: a review. Australian Journal of Experimental Agriculture, v.37, n.4, p.485-504, 1997.

BORTOLETTO, D.B.; NERES, M.A.; GARCIA, C.A. et al. Efeito da suplementação alimentar com feno de alfafa no desempenho de cordeiros em aleitamento. In: SIMPÓSIO DE INICIAÇÃO CIENTÍFICA, 1., 1997, Marília. Anais... Marília: Universidade de Marília, 1997. p.39.

GARCIA, C.A.; MONTEIRO, A.L.G.; COSTA, C. Produção de cordeiros Suffolk criados e terminados em creep feeding. $\mathbf{O}$ Berro, n.46, p.35-42, 2001.

HADJIPANAYIOTOU, M. Composition of ewe, goat and cow milk and of colostrum of ewes and goats. Small Ruminant Research, v.18, p.255-262, 1995.

JOHNSTON, C. Influence of milk- and grain-based creep feed formulations on feed intake and weight gain of suckling lambs to be weaned at 28 days of age. Sheep Research Journal, v.8, n.3, p.106-11, 1992. 
MACEDO, F.A.F. Desempenho e características de carcaças de cordeiros Corriedale e mestiços Bergamácia x Corriedale e Hampshire Down x Corriedale, terminados em confinamento. Botucatu: Universidade Estadual Paulista, 1998. 72p. Tese (Doutorado em Zootecnia) - Universidade Estadual Paulista, 1998.

MAHGOUB, O.; LU, C.D.; EARLY, R.J. Effects of dietary energy density on feed intake, body weight gain and carcass chemical composition of Omani growing lambs. Small Ruminant Research, v.37, p.35-42. 2000.

MATOS, M.S.; MATOS, P.F. Laboratório Clínico Médico Veterinário. 2.ed. Rio de Janeiro: Atheneu, 1988. 238p.

MOTTA, O.S. Ganho de peso, características da carcaça de cordeiros (as) sob diferentes métodos de alimentação, pesos ao abate e produção de leite das ovelhas. Santa Maria: Universidade Federal de Santa Maria, 2000. 76p. Dissertação (Mestrado em Zootecnia) - Universidade Federal de Santa Maria, 2000.

NATIONAL RESEARCH COUNCIL - NRC. Nutrient requirements of sheep. Washington, D.C.: National Academy Press, 1985. 99p.

NATIONAL RESEARCH COUNCIL - NRC. Nutrient requirements of domestic animals. Washington, D.C.: National Academy Press, 1968. 63p.

NERES, M.A.; GARCIA, C.A.; MONTEIRO, A.L.G. et al. Níveis de feno de alfafa e forma física da ração no desempenho de cordeiros em creep feeding. Revista Brasileira de Zootecnia, v.30, n.3, p.941-947, 2001a.

NERES, M.A.; MONTEIRO, A.L.G.; GARCIA, C.A. et al. Forma física da ração e pesos de abate nas características de carcaça de cordeiros em creep feeding. Revista Brasileira de Zootecnia, v.30, n.3, p.948-954, 2001b.

NERES, M.A. Níveis de feno de alfafa e forma física da ração no desempenho e características de carcaça de cordeiros em creep feeding. Botucatu: Universidade Estadual Paulista, 2000. 53p. Tese (Doutorado em Zootecnia) - Universidade Estadual Paulista, 2000.

NETO, M.J.L.; CUNHA, E.A. Comparação de métodos estimativos da produção de leite de ovelhas à pasto. Boletim da Indústria Animal, v.51, n.2, p.139-142,1994.

OCKERMAN, H.W.; EMSEM, H.; PARKER, C.F. et al. Influence of type (wooled or hair) and breed on growth and carcass characteristics and sensory properties of lamb. Journal of Food Science, v.47, p.1365-72, 1982.

OLIVEIRA, M.E.; ALENCAR, A.L.G.; NASCIMENTO, et al. Recria e terminação de ovinos em pastagem Cynodon spp. Cv. Tifton-85. In: REUNIÃO ANUAL DA SOCIEDADE BRASILEIRA DE ZOOTECNIA, 38., 2001, Piracicaba. Anais...Piracicaba: Sociedade Brasileira de Zootecnia, 2001. p.1051-1052.

OTTO, C.; BONA, A.F.O.; SÁ, J.L. et al. Efeito do desmame aos 45 e 60 dias de idade no desenvolvimento de cordeiros. CONGRESSO BRASILEIRO DE MEDICINA VETERINÁRIA, 23., 1994, Olinda. Anais... Olinda: CBMV, 1994. p.55.
PEREIRA, J.R.A.; SANTOS, I.C. Sistema intensivo para produção de carne ovina. In: PEREIRA, J.R.A.; SANTOS, I.C.; VENANCIO, W.S. Produção de ovinos. Ponta Grossa: Universidade Estadual de Ponta Grossa, 2001. p.7-19.

PREZIUSO, G.; RUSSO, C.; CASAROSA, L. et al. Effect of diet energy source on weight gain and carcass characteristics of lambs. Small Ruminant Research, v.33, p.9-15, 1999.

REIS, W.; JOBIM, C.C.; MACEDO, F.A.F. et al. Características de carcaça de cordeiros alimentados com dietas contendo grãos de milho conservados em diferentes formas. Revista Brasileira de Zootecnia, v.30, n.4, p.1308-1315, 2001.

SANTRA, A.; KARIM, S.A. Effects of protein levels in creep mixture on nutrient utilization and growth performance of pre-weaner lambs. Small Ruminant Research, v.33, p.131-136, 1999.

STATISTICAL ANALYSIS SYSTEM - SAS. User's guide: Statistics. 5.ed. Cary: 1985. 955p.

SILVA, D.J. Análise de alimentos (Métodos químicos e biológicos). Viçosa, MG: Universidade Federal de Viçosa, 1981. $166 \mathrm{p}$.

SILVA SOBRINHO, A.G. Aspectos quantitativos e qualitativos da produção de carne ovina. In: Produção animal na visão dos Brasileiros. REUNIÃO ANUAL DA SOCIEDADE BRASILEIRA DE ZOOTECNIA, 38., 2001, Piracicaba. Anais...Piracicaba: Sociedade Brasileira de Zootecnia, 2001. p.425-446.

SIQUEIRA, E.R.; SIMÕES, C.D.; FERNADES, S. Efeito do sexo e do peso ao abate sobre a produção de carne de cordeiro 1. Velocidade de crescimento, caracteres quantitativos da carcaça, pH da carne e resultado econômico. Revista Brasileira de Zootecnia, v.30, n.3, p.844-848, 2001.

SIQUEIRA, E.R.; AMARANTE, A.F.T.; FERNADES, S. Estudo comparativo da recria de cordeiros em confinamento e pastagem. Revista Veterinária e Zootecnia, v.5, p.17-28, 1993.

SUSIN, I. Exigências nutricionais de ovinos e estratégias de alimentação. In: SILVA SOBRINHO, A.G.; BATISTA, A.M.V.; SIQUEIRA, E.R. et al. Nutrição de ovinos. Jaboticabal: Fundação Estadual Paulista, 1996. 258p.

VILLAS BÔAS, A.S. Idade à desmama e manejo alimentar na produção de cordeiros superprecoces. Botucatu: Universidade Estadual Paulista, 2001. 55p. Dissertação (Mestrado em Zootecnia) - Universidade Estadual Paulista, Botucatu, 2001.

WILSON, L.L.; VARELA-ALVAREZ, H.; HESS, C.E. et al. Influence of energy level, creep feeding and lactation stage on ewe milk and lamb growth characters. Journal of Animal Science, v.33, n.3, p.686-90, 1971.

Recebido em: 28/05/02

Aceito em: 24/03/03 